\title{
Parasitic Worms of Man and Methods of Suppressing Them.
}

By Major F. H. Stewart, Indian Medical Service (Retired).

$\mathrm{O}^{\mathrm{N}}$ $\mathrm{NE}$ of the most interesting and important groups of the animal kingdom is that of the parasitic worms or helminths; interesting from the point of view of pure science on account of the intricate and varied nature of their life-histories and biological relationships, and important from the effects which they produce on the health of man, domestic animals, and cultivated and useful plants. In the present article a summary is attempted of the results of modern research on the helminths attacking man alone.

The more important helminths attacking human beings can be grouped as follows: (I) the intestinal worms, such as the roundworm and the hookworms, (2) the trematodes or flukeworms, and (3) the filarias and their allies, which live in the connective tissues.

The roundworm (Ascaris lumbricoides) and the hookworms (Ancylostoma duodenale and Necator americanus) live in the small intestine of man. The former is an animal of considerable size, from 20 to $35 \mathrm{~mm}$. in length, while the latter two are smaller, ro to $I_{3} \mathrm{~mm}$. long. The sexes are separate in all of them, and the females pour out a stream of eggs which are passed out of the human body in the fæces. The eggs ultimately find their way to the surface of the soil, and if the conditions are favourable-i.e. if the ground be moist and the temperature not less than that of a European summer (for Ascaris) or of an Egyptian summer (for Ancylostoma) - a small embryonic worm appears within the tough shell. The hookworm larvæ now hatch and lead a free life in mud or in small puddles or pools. Their attack on man is direct and active, for, should the hands or unshod feet come into contact with the mud or water which they inhabit, the little needle-shaped larvæ are roused to great activity. They bore their way through the skin into the subcutaneous tissue, and are carried in the lymphstream and blood through the heart to the lungs; from the lungs they swim up the air passages and down the osophagus, so reaching the small intestine. This remarkable life-history was worked out by the Austrian zoologist Looss in Cairo, and, although at first received with some scepticism, it has now been fully confirmed.

In the roundworm, on the other hand, the egg must be swallowed before it will hatch, and this accident (unfortunate from man's point of view) takes place through the consumption of vegetables grown on infected soil, on which eggs have been splashed, or as the result of eating with unwashed hands after working on contaminated land. When the egg arrives thus passively in the small intestine of man, it hatches, and a little larval worm emerges. Until recently it was supposed that this larva remained in the small intestine and simply grew to adult size without further adventure, but the present writer has been able to show that this is not so. The larva bores into the wall of the bowel, enters a vein, and, passing through the liver and heart in the bloodstream, reaches the lungs ; from the lungs it migrates to the intestines by a route similar to that adopted by the hookworm.

In the hookworm one object of the migration is obvious, since the larva is merely taking the most sure and direct route to its goal-that is, from the first point at which it comes into contact with man, be this the skin of hands or feet, or of any other part of the body, to the small intestine. It is true that from the finger-tips it might be carried to the mouth and so reach the intestine directly, but only a small percentage of those larvæ which have succeeded in finding man could count on this fortunate chance. By skin penetration, on the other hand, a high percentage should succeed, and it must be remembered that only a few of all the larvæ which have hatched ever succeed in finding man, while only a few of the eggs reach such favourable surroundings as allow the larvæ to form or to hatch.

There is, however, a second object for the migration of the hookworm, the one which is the only motive in the case of Ascaris-namely, that the young larva is not adapted to survive among the strong digestive juices. The young Ascaris lacks not only a stout cuticle, but also that power of chemical defence by which the older parasite resists digestion by its host. Both cuticle and constitutional resistance are developed during the migration, while the larva is being nursed by the blood and lymph, by the bland and nourishing juices of its host. It seems that direct invasion through the skin was the line of attack by the primitive ancestral parasitic worms, and that the present physiological necessity of the migration is due to inheritance.

In geographical distribution Ascaris lumbricoides is cosmopolitan, occurring in all lands both temperate and tropical. The hookworms are also very widely distributed, being absent only from the colder parts of the temperate zones. Even there they occur sporadically in artificially warm situations, such as mines and tunnels; the well-known outbreaks of " miners' anæmja," both in the mines of England and the Continent, e.g., in the St. Gothard tunnel, were due to this cause. The proportion of the population affected, especially in the tropics, is extraordinarily high, figures of from 40 to 98 per cent. having been recorded in various countries from the examination of large numbers of the populace. The degree of infestation is highest in the Far East-in China, IndoChina, the Dutch East Indies, and particularly in the tropical Pacific islands. The West Indies and tropical South America also return high percentages, while the southern States of the American Union yield figures which prove that it is not only among dark-skinned races that the parasites become very numerous. Even in Europe 20 per cent of the adult population of Italy and one-half of the children of Central Europe carry the roundworm.

The flukes are flattened oval worms which live in the veins of the abdomen (Bilharzia), in the bileducts and gall-bladder (Clonorchis), and in the tissues of the lungs (Paragonimus). Bilharzia occurs over large areas of the tropics and sub-tropics. Three species are known from man, one of which occurs in Mesopotamia, Egypt, and East Africa, the second in Central and South America, the West Indies, and West Africa, and the third in Japan, China, and the Philippines: The association of the West Indies and South America 
in one geographical area with West Africa also occurs in the distribution of Necator americanus, but is due, not to an old Atlantic connection between the two continents, but to the spread of African parasites to America by the slave trade. In Egypt more than one-half of the population are affected by Bilharzia. Clonorchis and Paragonimus are limited to the Far East-Indo-China, the Philippines, China, and Japan.

The life-histories of all the flukes are similar. The eggs are passed out with the fæces, and if they reach water, the embryos which they contain emerge and swim about actively in search of some particular small mollusc (the intermediate host) into which they must penetrate in order to undergo their first metamorphosis. The intermediate hosts are different in various countries, and for the several worms concerned; for Bilharzia, in the Far East, it is the small water snail, Katayama nosophora. This fact was first established by Miyairi and Suzuki, and was confirmed by Leiper and Atkinson ; later Leiper and his colleagues identified the intermediates in Egypt as Bullinus contortus, B. Dyborsski, and Planorbis Boissyi. From the snail Bilharzia escapes as a more advanced free-swimming larva, which can bore through the skin of man should he venture into infected waters, and, once within the body, it migrates through the tissues to the veins of the liver and abdomen.

For Clonorchis and Paragonimus the first intermediate host is also a small snail, Melania libertina. They do not transfer themselves directly and actively from this animal to man, but to a second intermediateClonorchis to various species of carp, and Paragonimus to freshwater crabs. In these animals, the second intermediate hosts, they remain passive until they are swallowed by man in food.

The filarias are long, threadlike worms which live in the connective tissues of various regions of the body. They are associated with the disease known as elephantiasis. Geographically they are spread throughout the whole of the tropics. The larva circulate in the blood in enormous numbers, and are taken up by bloodsucking insects, in which they grow in size; after the lapse of several days they wander into the proboscis, from which they are injected into the skin of man when the infected insect again feeds. The pioneer work on this subject was done by Manson, and later extended by Low, James, and Leiper. The most important species are Filaria Bancrofti, the larvæ of which are carried by various mosquitoes (Culex, Anopheles, and Stegomya), and Loa loa, carried by the mangrove fly Chrysops.

The guinea-worm, Dracunculus medinensis, is common in India, Turkestan, Persia, Arabia, and tropical Africa. It lives under the skin, and when mature gives rise to a small ulcer, generally on the leg or foot, from which one end of the worm projects. A stream of larvæ is discharged through this ulcer into water when the patient bathes. The next stage of its life is passed in a water flea, Cyclops, and it is by drinking water containing these minute crustacea that man is infected.

Apart from local disease such as abscesses, elephantoid swellings, hæmaturia, etc., the more important helminths produce generalised disease of a very important nature which is surprisingly uniform, whatever be the causal animal. The primary symptom is always anæmia, and the secondary symptoms are such as accompany this condition, namely, general weakness, inability for work or any exertion, disturbance of the heart and circulation, and finally dropsy and death. In mild cases, which fortunately are the most common, the anæmia is not great, and the patient is merely reduced to a lower level of activity, happiness, and efficiency. But when we consider the enormous prevalence of these pests, we can realise the extent of the harm inflicted on mankind by them. It miust also be remembered that in most tropical countries the people live only just above starvation level, and that any additional burden will quickly depress them below it. The means by which this anæmia is produced is not clearly understood, but recent work points to the formation of poisonous secretions, toxins, by the worms, which damage both the blood and the blood-forming organs. Bedson has shown that the injection of worm extracts produces acute inflammation of the thyroid, suprarenal capsules, and spleen.

Our armament for offence and defence against these enemies is at present incomplete, but it is becoming more effective. Offensive measures consist in attacking the parasites directly in the bodies of their human hosts, and the main advances have been in the use of oil of Chenopodium against the intestinal worms, Ascaris and Ancylostoma, and the intravenous injection of tartrate of antimony against Bilharzia. The former drug can be used on an enormous scale with great safety and efficiency, and if the inhabitants of a badly infected country can be educated to the point of undergoing treatment en masse once a year, a great reduction of disease should result. The second discovery, which we owe to Christopherson, has, at least in theory, entirely changed the future of whole nations. A disease which was previously incurable, and in Egypt, for instance, affects one-half of the people, can now be cured with certainty in a few months. In dealing with ignorant and suspicious native races, however, the rapid adoption of such strange and terrifying methods cannot be expected.

For defensive measures reliance is placed on improvements in sanitation and in the personal cleanliness of the people, advances which will necessarily be slow. No practical means of destroying eggs or larvæ on a large scale in the outer world have yet been discovered. Where an intermediate host exists a reduction of the disease would follow wholesale destruction of, or protection against, the intermediate. In this connection, mosquito destruction has of course already been carried out on a large scale in anti-malaria work in many regions, and it may be extended with the additional object of fighting worm disease. For the destruction of the snails associated with fluke disease periodical drying of canals and irrigated fields has been advocated by Leiper. The knowledge that Clonorchis and Paragonimus are introduced in food should also make the avoidance of these parasites easy.

Three things are above all necessary for the conquest of these plagues: (I) Continued and intensified research into the many points of the intricate lifehistories of these parasites and their intermediate hosts which are still obscure ; into new methods of destruction, chemical and physical, of both these groups of animals, whether as eggs, larvæ, or adults ; and into

NO. 2734, VOL. IO9] 
new methods of medical treatment for infected man. (2) Systematic instruction and tactful control of the peoples affected. This will be the duty of the medical and teaching professions of the stricken countries. Anyone who has watched the increase of well-taught and capable physicians in such a country as India during the last twenty years will base great hopes on the growth of this influence. (3) And most important, a common and indignant consciousness that these plagues are not inevitable, that by combined effort they can be cast off, and that it is a disgrace to humanity that one-half of its members should be harbouring these loathsome parasites.

\section{The Theory of Relativity in Relation to Scientific Method. ${ }^{1}$}

By Dr. Dorothy Wrinch, Fellow of Girton College, Cambridge.

SOME interesting criticisms of the theory of rela$\checkmark$ tivity have been advanced recently by M. Paul Painlevé, in two papers in the Comptes rendus de l'Académie des Sciences de Paris. ${ }^{2}$ M. Painlevé attacks the theory as it at present stands, on grounds which are of general scientific interest. $\mathrm{He}$ criticises the expression for $d s$, the element of length adopted by Einstein,

$$
d s^{2}=d t^{2}(\mathrm{I}-a / \gamma)-r^{2}\left(d \theta^{2}+\sin ^{2} \theta d \phi^{2}\right)-d r^{2} /(\mathrm{I}-a / \gamma)
$$

on the ground that it is one of a very large number of forms which satisfy the Einstein conditions. He cites some of the other possible forms for the relation between the length element and the four co-ordinates $(r, \theta, \phi, t)$, and indicates the various consequences which ensue according to the particular form adopted.

At this point we encounter, as M. Painlevé points out, a serious difficulty; but it is a difficulty which is present in all scientific investigations. The botanist plotting on paper the results of experiments which were designed to discover the relation between two variables, $x$ and $y$, is faced by the same problem when he decides on the method to be adopted in interpolation. For his experiments merely tell him that, whatever the relation between the variables may be, the function connecting them must be such that when $x=x_{r}$, we also have $y=y_{r}$, where $\left(x_{1}, y_{1}\right),\left(x_{2}, y_{2}\right) \ldots\left(x_{r}, y_{r}\right) \ldots$ $\left(x_{n}, y_{n}\right)$ represent, roughly speaking, the results of his experiments. But the number of his observations is necessarily finite; and it is evident that there are at least as many functions satisfying these conditions as there are points in the mathematical continuum. This difficulty of choosing between a set of functions all of which satisfy the data of the problem presents itself at several critical points of the Einstein theory. It is entirely plain that if science is to be possible, some further principle is required.

\section{The Simplicity Postulate.}

In the face of this difficulty, it has been the practice of scientific writers to choose the simplest function available. The question of what constitutes simplicity, or rather the question of when one function is simpler than another, is a difficult one, but in ordinary scientific work, and especially in biology, the term is considered to be well understood. In selecting the simplest alternative, no one, of course, would hold that the other alternatives are impossible. Indeed, the simplicity

1 Paper read before the Congress of Philosophy in Paris on December 29, $192 \mathrm{I}$ "

2 " $\mathrm{La}$ Mécanique classique et la théorie de la relativité," October 24, 1921 ; "La Gravitation dans la mécanique de Newton et dans la mécanique d'Einstein," November I4, I92I. criterion arranges the various possibilities in serial order. If the first of this set afterwards proves unsuitable, the next one is taken, and so on. Thus, in outline, we may say that the procedure of science is to attach probabilities to the various functions in such a way that the probabilities of functions arranged in order of simplicity decrease rapidly to zero, so that there is little probability of any of the more complicated functions which could be devised being the correct one.

In criticising this procedure from a logical point of view, it will be of no avail to demand, at the outset, a definition of the relation involved in the proposition that one function is simpler than another. Common sense uses the notion of simplicity, and we cannot go behind common sense. The business of the logician is to interpret it and relate its various beliefs inter se, eliminating when necessary the less fundamental beliefs in favour of those which are held more firmly and the deductions which can be drawn from these beliefs. But this absence of definition makes it important to consider the way in which the simplicity postulate is used in relativity theory. M. Painleve discusses some of the alternative forms for the length element, to which he sees no objection. He shows that some of them carry with them consequences as to the change in dimensions of a moving body which are mutually inconsistent and in direct contradiction to the Einstein theory. It may therefore be possible to make a choice between some of them by means of data of this kind, and consequently to settle the controversy as to the form of $d s$, at least to the extent of eliminating those forms which give certain types of change in the dimensions of bodies in motion. M. Painlevé states that he considers some of his forms to be as simple as the form adopted by Einstein. In the absence of a decision being reached by means of further data, the objection of M. Painlevé will fall to the ground only if it is established that the form which Einstein has used for the length element is the simplest one which fits the facts of the external world.

\section{The Value of Comprehensiveness.}

There is another logical property which enables us to assign a value to rival scientific theories. In choosing between various ways of relating facts inter se, we shall evidently prefer theories which group together the largest number of facts under one set of assumptions. Comprehensiveness is, indeed, an important test of the value of a theory, for as the number of facts which are linked together by a theory increases, the theory grows in importance as a

$$
\text { NO. 2734, VOL. 109] }
$$

